This is a postprint version of the article:

Sirola, A., Kaakinen, M., \& Oksanen, A. (2018,34(4), pp. 1313-1325). Excessive

gambling and online gambling communities. Journal of Gambling Studies,

DOI: 10.1007/s10899-018-9772-0.

http://dx.doi.org/10.1007/s10899-018-9772-0

Sirola, Anu, Kaakinen, Markus, Oksanen, Atte

University of Tampere, Faculty of Social Sciences

\title{
Excessive gambling and online gambling communities
}

\begin{abstract}
The Internet provides an accessible context for online gambling and gambling-related online communities, such as discussion forums for gamblers. These communities may be particularly attractive to young gamblers who are active Internet users. The aim of this study was to examine the use of gambling-related online communities and their relevance to excessive gambling among 15-25year-old Finnish Internet users $(\mathrm{N}=1200)$. Excessive gambling was assessed by using the South Oaks Gambling Screen (SOGS). Respondents were asked in a survey about their use of various kinds of gambling-related online communities, and sociodemographic and behavioral factors were adjusted. The results of the study revealed that over half $(54.33 \%)$ of respondents who had visited gamblingrelated online communities were either at-risk gamblers or probable pathological gamblers. Discussion in these communities was mainly based on sharing gambling tips and experiences, and very few respondents said that they related to gambling problems and recovery. In three different regression models, visiting gambling-related online communities was a significant predictor for excessive gambling (with 95\% confidence level) even after adjusting confounding factors. The association of visiting such sites was even stronger among probable pathological gamblers than among at-risk gamblers. Health professionals working with young people should be aware of the role of online communities in terms of development and persistence of excessive gambling. Monitoring the use of online gambling communities as well as utilizing recovery-oriented support both offline and online would be important in preventing further problems. Gambling platforms should also include warnings about excessive gambling and provide links to helpful sources.
\end{abstract}

Keywords: gambling, excessive gambling, internet, online communities

\section{Introduction}

Digital and technological advancements, such as increased opportunities for online gambling, have had a major impact on the nature of gambling (Gainsbury et al. 2015). The amount and use of online gambling sites, such as online casinos, have grown significantly over the past decade (Gainsbury et al. 2015; King et al. 2010; Raisamo et al. 2013), and particularly online poker has gained popularity (Biolcati et al. 2015; Griffiths et al. 2010). Online gambling has various context-specific risk factors, such as constant availability and accessibility, anonymity and privacy, and electronic money transfers (Gainsbury et al. 2015; Griffiths 2003). Particularly, young gamblers are at a high-risk to be exposed to and engage in online gambling and experience significant problems (Gainsbury et al. 2015; King 
et al. 2010; Raisamo et al. 2013). This is partly due to their high involvement with the Internet and social media in general (De Freitas and Griffiths 2008) and the relative ease of gambling without surveillance or age-restrictions on gambling websites (Cotte and LaTour 2008). Gambling is also widely advertised and promoted online, which may increase gambling consumption and its positive stance (Binde 2009b; Hing et al. 2014).

In addition to gambling sites, the Internet and social media provide an efficient context for interaction with, dissemination of, and exposure to various gambling-related user-generated online content. A prominent example of this are various kinds of social networking communities such as discussion forums for gamblers (Caputo 2015; Mudry and Strong 2013; O'Leary and Carroll 2013). Together with online gambling sites, these forums of networking and content sharing can form ecosystems of interconnected gambling-related platforms. Socializing with other players may also be a motivational factor for increased gambling and consequently lead to excessive forms of gambling (Corney and Davis 2010; O'Leary and Carroll 2013). Although the existence of gambling-related online communities has been acknowledged, more research is needed on the use of these communities and their potential relevance to excessive gambling among young people. This study examines excessive gambling from a social psychological perspective, focusing on the social dimension of online gambling communities and their attractivity to young gamblers.

Excessive gambling is treated as a form of addictive or an excessive mode of behavior (Orford 2001), covering potentially risky, problematic and pathological forms of gambling. From a medical perspective, excessive gambling is defined as an addiction characterized by high involvement in gambling activities despite adverse consequences (Binde 2009a; Orford, 2001). The diagnostic criteria in the DSM-IV categorizes pathological gambling and its milder form, problem gambling, as impulse control disorders (see Castrén et al. 2013). In the fifth revision of the DSM, pathological gambling was moved to substance-related and addictive disorders and named as "gambling disorder," with classifications of mild, moderate and severe (Petry et al. 2013; Sleczka et al. 2015). Also, the current beta draft of forthcoming ICD-11 revised "pathological gambling" as "gambling disorder" (WHO 2017). Gambling and substance-related disorders have many similarities, such as craving and loss of control (Romanczuk-Seiferth et al. 2014), and disordered gambling also has high comorbidity with hazardous alcohol and drug use, as well as mood and anxiety disorders (Castrén et al. 2013; Lorains et al. 2011; Martin et al. 2014; Petry et al. 2005).

Studies show that at-risk gambling and pathological gambling are more common among men than women (Blanco et al. 2006; Hing et al. 2016b; Petry et al. 2005; Salonen and Raisamo 2015). Excessive gambling is also associated with having financial problems, such as taking instant loans (Lind et al. 2015; Worthy et al. 2010). In addition to psychiatric pathology, excessive gambling can be conceived as a multidimensional phenomenon that includes a complex interaction between individual, social and environmental factors in terms of gambling motivation, involvement and developing possible problems (Binde 2009a; Blaszczynski and Nower 2002). For example, a lack of perceived social support from primary groups, such as family and friends, is associated with developing and maintaining gambling-related problems (Hardoon et al. 2004; Petry and Weiss 2009).

Despite that gambling activities are in many countries illegal for underaged people, a review by Calado et al. (2017) shows that gambling is a popular activity among adolescents, and that approximately $0.2-12.3 \%$ of young people have gambling problems. Youth gambling and problem gambling are worldwide concerns (Calado et al. 2017; Volberg et al. 2010) and additional research is thus needed, particularly in countries with high gambling and problem gambling prevalence. In Europe, Finland represents one of the highest gambling prevalence rates (Calado et al. 2017; Salonen and Raisamo 2015). According to the Finnish National Institute for Health and Welfare (THL), 
gambling activity among Finnish people typically starts at the age of 16, and gambling problems are most common in the 18-24-year-old age group (Salonen and Raisamo 2015).

In addition to high problem gambling prevalence, young people are also active social media users, which may further reinforce gambling behavior and positive stance on gambling. Young people tend to form strong social bonds in online communities, and online peer networks and the content shared within them may also have major impacts on young users' behaviors (Huang et al. 2014; Lehdonvirta and Räsänen 2011) and risk-taking (Hoorn et al. 2017). From users' point of view, online gambling communities are safe environments that are based on a mutual identity and interaction with likeminded others, countering the potential lack of understanding and social support in offline settings (Mudry and Strong 2013; O'Leary and Carroll 2013). However, use of the Internet itself can become addictive (Kuss et al. 2014; Van Rooij and Prause 2014), and it is known that high use of the Internet and technology is related to excessive gambling (Phillips et al. 2012; Spada 2014). In terms of risky health behaviors, a study by Syed-Abdul et al. (2013) revealed that user-generated online content is more appealing to young users than information from health authorities. User-generated online communities serve as important identification contexts for young people; thus, research is needed to examine their potential role regarding risky health behaviors. Gambling-related communities may have an analogous role for young people.

When examining potential risks, it is also important to acknowledge that online gambling communities have differing stances on gambling and its acceptability. Some gambling communities such as poker forums focus on promoting and sharing gambling strategies, tips and knowledge between users (O'Leary and Carroll 2013; Parke and Griffiths 2013). These kinds of communities can contribute to the spread and normalization of gambling on other risk behavior (Daine et al. 2013; O'Leary and Carroll 2013). They can also help develop cognitive biases concerning gambling, such as the illusion of control (Parke and Griffiths 2013), which has been linked to severe gambling problems (Barrault and Varescon 2013). However, there are also gambling communities based on recovery-oriented peer-support for gambling problems (Caputo 2015; Gainsbury and Blaszczynski 2011; Mudry and Strong 2013). These kinds of recovery-oriented platforms may be beneficial for developing a recovery identity and overcoming addiction (McNamara and Parsons 2016; Mudry and Strong 2013). Thus, depending their norms and belief-systems concerning gambling, communities offer different kinds of identification contexts for gambling-involved online users. For a community user, it is important to conform to community's norms and shared belief systems to become a socially accepted member of a community (O'Leary and Carroll 2013). Thus, in terms of gambling problems, it is crucial what kinds of communities a user becomes identified with.

\section{The Current Study}

In past studies, the existence of gambling-related online communities has been suggested as a potential motivating factor for excessive gambling (Corney and Davis 2010; O'Leary and Carroll 2013), but little is known about who uses these communities or their relevance to at-risk or probable pathological gambling. It is also important to gain more knowledge on online gambling behavior by younger age groups, as currently, those born in the 1990s and the 2000s are the first generations growing up with social media. The main aim of this study is to analyze the association between the use of gambling-related online communities and excessive gambling. As previous studies showed, use of online communities may encourage young people for risk behavior (Daine et al. 2013; Huang et al. 2014). Therefore, it was hypothesized that the use of gambling-related online communities is associated with excessive gambling. 


\section{Method}

\section{Participants and procedures}

The participants of this study included a demographically balanced sample of Finnish participants, aged 15 to $25(\mathrm{n}=1200,50 \%$ male, mean age $=21.29, \mathrm{SD}=2.85)$. The participants were recruited from a pool of volunteer respondents administrated by Survey Sample International (SSI) from March to April 2017. The pool of respondents mirrored sociodemographic measures of age, gender and regional area type of Finnish young people of the same age. Age, gender and residential area structure of the sample are close to the Finnish population aged 15-25 (see Statistics Finland, 2016).

All participants responded to a YouGamble online survey that was designed to study online gambling from social psychological perspective. The survey questionnaire was constructed using Limesurvey software, and it was optimized for both computers and mobile devices. The median response time for the survey was 15.50 minutes.

The Academic Ethics Committee of the Tampere Region reviewed the research proposal in December 2016 and stated that the research does not include any ethical problems (decision 62/2016). All participants were informed about the aims of the study and the use of the data.

\section{Measures}

Excessive gambling. The South Oaks Gambling Screen (SOGS) was used to measure excessive gambling. SOGS is based on DSM-III and DSM-IV criteria for pathological gambling (Lesieur and Blume 1987) and is among the most widely used screeners for problem gambling (Shaffer et al. 1999). It is also widely used in Finnish studies involving populations of 15 to 25 (Castrén et al. 2013; Edgren et al. 2016; Salonen and Raisamo 2015). In addition to DSM-III and DSM-IV criteria, the measure is also reported as having a strong correlation with DSM-V symptoms (Goodie et al. 2013). Within this study, the SOGS scores ranged from 0 to 20, and the Cronbach alpha for SOGS was .89. Standard cutoffs were used for SOGS: 0-2 = no problem gambling, 3-4 = at-risk gambling, $\geq 5=$ probable pathological gambling (e.g. Castrén et al. 2013). Because the cutoff of $\geq 5$ for probable pathological gambling has been discussed in the literature due to potentially excessive false positives, additional analyzes were run based on DSM-V criteria and a cutoff of $\geq 8$ for gambling disorder (Goodie et al. 2013). These categorical variables were used in the analysis as dependent variables.

Online gambling communities. The use of online gambling communities was asked with the question: "How often do you use gambling-related discussion forums or communities?" The answer options were "never," "seldom," "daily" and "many times a day." The answers were categorized as a dummy variable $(0=$ no i.e., "never," $1=$ yes i.e., at least "seldom"). Those who answered that they used these communities at least seldomly were given an additional multiple-choice question about what the discussion on these sites usually related to. The options were "gambling tips," "users' gambling experiences," "gambling problems and recovery," "gambling in general" and "other issues." The respondents were able to select multiple options.

Sociodemographic controls included gender and age. Age was categorized into three categories (1517, 18-21 and 22-25), and the youngest age group was used as a reference category in the models. Survey also included a self-reported measure of whether participants had taken instant loans.

Control factors included both behavioral and attitudinal measures related to problem gambling. First of all, visiting online casino sites was controlled. This was asked with the question: "How often do 
you use betting agencies or online casino sites? (e.g., Veikkaus, NettiCasino)". The answer options were "never," "seldom," "daily" and "many times a day." The answers were categorized into a dummy variable ( $0=$ no i.e. "never," $1=$ yes i.e. at least "seldom"). Other controls included hazardous drinking (3-item AUDIT-C, range $0-3, \alpha=82$ ) and compulsive Internet use (14-item Compulsive Internet Use Scale, range 0-56, $\alpha=.93$; see also Meerkerk et al. 2009). Models for belonging to primary groups were also adjusted. This was measured with three items: "How closely do you feel to belong to each of the following? A) Family, B) friendship group, C) school or work community." The scale varied from 1 ("not at all close") to 10 ("very close"). These measures were combined to form a composite variable (range $3-30 ; \alpha=.75$ ).

\section{Statistical techniques}

The analyses were carried out by using Stata 12 software. First, descriptive statistics on not-at-risk gamblers, at-risk gamblers and probable pathological gamblers were provided. To adjust the potential confounding factors, a multinomial logistic regression was run. Age- and gender-adjusted results are reported in the text, and Table 2 includes the final models. No at-risk gambling was used as a reference. Relative risk ratios (RRR), standard errors (SE) and the statistical significance of results (p) are reported. Additional model fit statistics include pseudo-coefficients of determination and likelihood ratio $\chi^{2}$ test statistics. Additional analyses were run with linear ordinary least square (OLS) regression as a further confirmation of the results and is only reported in the text.

\section{Results}

Out of 1,200 respondents, $10.83 \%$ reported probable pathological gambling (SOGS $\geq 5$ ), 10.33\% $(\mathrm{SOGS}=3-4)$ reported at-risk gambling and $78.83 \%$ did not report at-risk gambling (Table 1). The findings showed that $14.42 \%$ of the respondents had participated in online gambling communities. The discussions in such communities included gambling tips $(46.82 \%, 81 / 173)$, gambling experiences $(29.48 \%, 51 / 173)$, gambling in general $(52.60 \%, 91 / 173)$ and other issues $(16.18 \%, 28 / 173)$. Very few of the respondents said that discussions were related to gambling problems and recovery $(9.25 \%$, 16/173). The visitors of gambling-related communities were more often males than females $(\mathrm{p}<.001)$. Age was not associated with visiting such sites.

Descriptive statistics showed that at-risk gamblers and probable pathological gamblers were more likely to visit gambling-related online communities. Out of those who had not visited these sites, only $15.58 \%$ reported at-risk gambling or probable pathological gambling, while for those who had visited gambling-related online communities, the respective figure was $54.33 \%$. The descriptive table also shows that both at-risk gambling and probable pathological gambling were more common among males and young people aged 18-21 than among others. Both results were also more common among those who had visited online casino sites and among those who had taken instant loans.

Multinomial logistic regression models were run to further investigate whether visiting gamblingrelated online communities could be considered a risk factor for at-risk gambling and probable pathological gambling. Age- and gender-adjusted models were run first, which confirmed that visiting gambling related online communities was positively associated with both at-risk gambling $(\mathrm{RRR}=2.76, p<.001)$ and probable pathological gambling $(\mathrm{RRR}=7.82, p<.001)$. The final models that included all the confounding factors confirmed these findings (Table 2). Adding numbers of confounders showed that visiting gambling-related online communities was positively associated with probable pathological gambling $(\mathrm{RRR}=2.91, p=<.001)$. 
The full model also indicated that both at-risk gambling and pathological gambling were more common among males than females and most common among the age group of 18 to 21 years old. In addition, taking instant loans, visiting online gambling casino sites and compulsively using the Internet were associated with both at-risk gambling and probable pathological gambling. It was also found that probable pathological gamblers reported weaker senses of belonging to primary groups. The full model was statistically significant $(p<.001)$ and had reasonably high pseudo-coefficients of determination (Nagelkerke $\mathrm{R}^{2}=.33$; McFadden $\mathrm{R}^{2}=.21$ ).

The additional analyses were run using an alternative cutoff point $(\geq 8)$ based on DSM-V criteria for gambling disorder (Goodie et al. 2013). Based on these criteria, 3.67\% reported disordered gambling (SOGS $\geq 8$ ), $10.33 \%$ reported at-risk gambling (SOGS $=3-7$ ) and $78.83 \%$ did not report at-risk gambling. These did not change the main results, as it was found that visiting gambling-related online communities was positively associated with both at-risk gambling ( $R R R=1.74, p=.013$ ) and disordered gambling $(\mathrm{RRR}=2.90, p=.005)$. This model is reported in Table 3. SOGS scores through a standard linear OLS regression were also run. The model included the same covariants as the multinomial logistic regression model and confirmed that visiting gambling-related online communities increased SOGS scores by $1.43(\beta=.20 ; p<.001)$. These results further confirmed the findings of this study.

\section{Discussion}

The aim of this study was to examine the use of gambling-related online communities and its relevance to excessive gambling among Finnish young people. It was found that over half $(54.33 \%)$ of the respondents who had visited gambling-related online communities were either at-risk gamblers or probable disordered gamblers. These communities were mostly based on mutual discussions about gambling and sharing gambling experiences and tips. Both descriptive statistics and regression models showed that visiting gambling-related online communities was a risk factor for excessive gambling. Further, the association of visiting such sites was even stronger among probable pathological gamblers than among at-risk gamblers. The models adjusted the number of sociodemographic and behavioral factors. Additional analyses based on DSM criteria and a SOGS cutoff point of 8 further confirmed these findings.

Results also supported previous research indicating that excessive gambling is more common among men than women (Blanco et al. 2006; Hing et al. 2016b; Petry et al. 2005; Salonen and Raisamo 2015) and among those who had taken instant loans (Worthy et al. 2010). Both problem and probable pathological gambling were more common among the age group of 18 to 21. Other Finnish studies have indicated that, during this period, severe financial problems in Finland increase dramatically, as young people are given opportunities for consumer choices and instant loans (Autio et al. 2009; Oksanen et al. 2016). Both hazardous drinking and compulsive Internet use were associated with probable pathological gambling, indicating that probable pathological gamblers have multiple problems (see also Blaszczynski and Nower 2002; Hardoon et al. 2004; Hartmann and Blaszczynski 2018; Petry et al. 2005).

Probable pathological gamblers also had weaker social belonging to primary groups, which supports previous research indicating that a lack of social support from family and friends is a risk factor for excessive gambling and other addictive behaviors (Hardoon et al. 2004; Petry and Weiss 2009). This is also in line with literature showing that online risks are taken by young people who may face problems in their offline lives (Livingstone and Helsper 2007; Mitchell et al. 2011; Noll et al. 2013). This study confirms that we should be especially worried about young people who use the Internet 
compulsively and lack proper social relationships and support in their offline networks. As such, the current study indicates that strong social ties to primary groups and investing in supportive offline relationships could protect young people from developing such problems.

People who suffer from excessive gambling and its negative consequences are prone to hide problems from others and seek support online instead (Gainsbury and Blaszcynski 2011; Mudry and Strong 2013). Indeed, only a minority of excessive gamblers seek professional help (Gainsbury et al. 2014). However, in this data, only very few participants of online gambling communities reported using communities related to gambling problems and recovery, while communities mostly concerned gambling tips and carried generally positive stance on gambling. This was partly surprising considering the existence of recovery-oriented gambling communities online has been acknowledged in studies (Caputo 2015; Mudry and Strong 2013). However, this result can be explained partly by the young age of respondents. Despite that many of respondents scored high in their problem gambling severity, young people may not recognize that their gambling is problematic (e.g. Splevins et al. 2010) or they can be unaware of sources that could help them (Gainsbury et al. 2014). Generally, young people might prefer engaging in sites and discussions that carry gambling-positive messages. For example, online poker carries a lot of glamor within popular culture, and there are many celebrities and young poker stars that may be a major influence for young people's gambling attitudes (Shead et al. 2011). However, online poker is not the only gambling activity among young people and thus, more research is needed to examine different gambling activities and their association with the use of online gambling communities.

Given the results of this study, it should be investigated how Internet and its social networking platforms could be utilized better in terms of gambling problem recovery among young people. For example, gambling sites and communities could include warnings about excessive gambling and provide links to helpful resources. Raising awareness particularly of online interventions and support groups for young problem gamblers would be beneficial, especially given that young people often prefer Internet as a source for help (Gainsbury et al. 2014; Monaghan and Wood 2010). Since excessive gambling, like other addictions, is a widely stigmatized phenomenon (Hing et al. 2016a; Horch and Hodgins 2008), stigma may increase reluctance to seek professional help (Gainsbury et al. 2014). Instead, online anonymity and the relative ease of finding others who are similarly minded may facilitate self-disclosure (Joinson 2001; Suler 2004) and even improve wellbeing (Best et al. 2014). Indeed, the beneficial role of online support groups and shared recovery identities have been acknowledged in terms of overcoming an addiction (see McNamara and Parsons 2016; Mudry and Strong 2013).

In online gambling ecosystems, various gambling sites provide unrestricted access to gambling while gambling communities such as discussion forums function as social platforms for discussion and content-sharing. Given the crucial roles of peer influence and online environment among young people, these social parts of gambling ecosystems are potential risk factors for developing and maintaining excessive gambling, particularly when interaction is based on promoting gambling behavior. Excessive gambling is a multidimensional phenomenon and has various motivational and involvement risk factors; however, not all people are likely to develop excessive gambling habits despite involvement in risky practices (Binde 2009a, pp. 65). This study indicates that using gambling-related online communities is associated with excessive gambling. High involvement in and identification with gambling-positive communities may normalize gambling behavior and reinforce cognitive biases and thus lead to development of problematic forms of gambling behaviors. Qualitative research would be valuable in examining what kinds of motivational aspects are present when seeking for, ending up to and identifying with different gambling-related online communities. 


\section{Limitations}

This study was cross-sectional, so it was impossible to investigate any kind of causal mechanisms or longer-term effects of gambling-related online communities. Longitudinal datasets on the phenomenon would be important but also demanding to collect. The study was also limited to a sample of Finnish young people aged 15 to 25. Hence, the results should not be generalized to older populations, and more studies would be needed to investigate whether the association is the same among older people. Finally, types of gambling activities and their association with the use of online gambling communities were not examined. Thus, it cannot be determined whether some forms of gambling, such as online poker, are more likely than others to be discussed in online gambling communities. This issue should be investigated in future studies.

\section{Conclusion}

Visiting gambling-related online communities is a risk factor for both at-risk gambling and probable pathological gambling, and the association of visiting such sites is even stronger among probable pathological gamblers than at-risk gamblers. Using gambling-positive sites and interacting with other gamblers may reinforce problematic gambling behavior and further inhibit help-seeking and recovery. Given the high use of the Internet and social media among young people, health professionals should be aware of online communities and their potential relevance with maintaining and developing problematic gambling habits. Monitoring the use of gambling-related online sites and communities among young problem gamblers as well as utilizing recovery-oriented support both offline and online would be important in preventing further problems. Gambling sites and communities should also include warnings about excessive gambling and provide links to online intervention programs and other helpful sources for problematic gambling.

\section{References}

Autio, M., Wilska, T. A., Kaartinen, R., \& Lähteenmaa, J. (2009). The use of small instant loans among young adults - A gateway to a consumer insolvency? International Journal of Consumer Studies, 33(4), 407-415.

Barrault, S., \& Varescon, I. (2013). Cognitive distortions, anxiety, and depression among regular and pathological gambling online poker players. Cyberpsychology, Behavior, and Social Networking, 16(3), 183-188.

Best, P., Manktelow, R., \& Taylor, B. (2014). Online communication, social media and adolescent wellbeing: A systematic narrative review. Children and Youth Services Review, 41, 27-36.

Binde, P. (2009a). Gambling Motivation and Involvement: A Review of Social Science Research. Stockholm: Swedish National Institute of Public Health.

Binde, P. (2009b). Exploring the impact of gambling advertising: An interview study of problem gamblers. International Journal of Mental Health and Addiction, 7(4), 541-554.

Biolcati, R., Passini, S. \& Griffiths, M.D. (2015). All-in and bad beat: Professional poker players and pathological gambling. International Journal of Mental Health and Addiction, 13(1), 19-32. 
Blanco, C., Hasin, D. S., Petry, N., Stinson, F. S., \& Grant, B. F. (2006). Sex differences in subclinical and DSM-IV pathological gambling: results from the National Epidemiologic Survey on Alcohol and Related Conditions. Psychological Medicine, 36(7), 943-953.

Blaszczynski, A., \& Nower, L. (2002). A pathways model of problem and pathological gambling. Addiction, 97(5), 487-499.

Calado, F., Alexandre, J., \& Griffiths, M. D. (2017). Prevalence of adolescent problem gambling: a systematic review of recent research. Journal of Gambling Studies, 33(2), 397-424.

Caputo, A. (2015). Sharing problem gamblers' experiences: a text analysis of gambling stories via online forum. Mediterranean Journal of Clinical Psychology, 3(1), 1-26.

Castrén, S., Basnet, S., Salonen, A. H., Pankakoski, M., Ronkainen, J. E., Alho, H., \& Lahti, T. (2013). Factors associated with disordered gambling in Finland. Substance Abuse Treatment, Prevention, and Policy, 8(24).

Corney, R., \& Davis, J. (2010). The attractions and risks of Internet gambling for women: A qualitative study. Journal of Gambling Issues, (24), 121-139.

Cotte, J., \& Latour, K. A. (2008). Blackjack in the kitchen: Understanding online versus casino gambling. Journal of Consumer Research, 35(5), 742-758.

Daine, K., Hawton, K., Singaravelu, V., Stewart, A., Simkin, S., \& Montgomery, P. (2013). The power of the web: a systematic review of studies of the influence of the internet on self-harm and suicide in young people. Plos One, 8(10), e77555.

De Freitas, S., \& Griffiths, M. (2008). The convergence of gaming practices with other media forms: what potential for learning? A review of the literature. Learning, Media and Technology, $33(1), 11-20$.

Edgren, R., Castrén, S., Mäkelä, M., Pörtfors, P., Alho, H., \& Salonen, A. H. (2016). Reliability of Instruments Measuring At-Risk and Problem Gambling Among Young Individuals: A Systematic Review Covering Years 2009-2015. Journal of Adolescent Health, 58(6), 600615.

Gainsbury, S., \& Blaszczynski, A. (2011). Online self-guided interventions for the treatment of problem gambling. International Gambling Studies, 11(3), 289-308.

Gainsbury, S., Hing, N., \& Suhonen, N. (2014). Professional help-seeking for gambling problems: Awareness, barriers and motivators for treatment. Journal of Gambling Studies, 30(2), 503519.

Gainsbury, S. M., Russell, A., Wood, R., Hing, N., \& Blaszczynski, A. (2015). How risky is Internet gambling? A comparison of subgroups of Internet gamblers based on problem gambling status. New Media \& Society, 17(6), 861-879. 
Goodie, A. S., MacKillop, J., Miller, J. D., Fortune, E. E., Maples, J., Lance, C. E., \& Campbell, W. K. (2013). Evaluating the South Oaks Gambling Screen with DSM-IV and DSM-V criteria: Results from a diverse community sample of gamblers. Assessment, 20(5), 523-531.

Griffiths, M. (2003). Internet gambling: Issues, concerns, and recommendations. CyberPsychology \& Behavior, 6(6), 557-568.

Griffiths, M., Parke, J., Wood, R., \& Rigbye, J. (2010). Online poker gambling in university students: Further findings from an online survey. International Journal of Mental Health and Addiction, $8(1), 82-89$.

Hardoon, K. K., Gupta, R., \& Derevensky, J. L. (2004). Psychosocial variables associated with adolescent gambling. Psychology of Addictive Behaviors, 18(2), 170-179.

Hartmann, M., \& Blaszczynski, A. (2018). The longitudinal relationships between psychiatric disorders and gambling disorders. International Journal of Mental Health and Addiction, 16(1), 16-44.

Hing, N., Cherney, L., Blaszczynski, A., Gainsbury, S. M., \& Lubman, D. I. (2014). Do advertising and promotions for online gambling increase gambling consumption? An exploratory study. International Gambling Studies, 14(3), 394-409.

Hing, N., Russell, A. M., Gainsbury, S. M., \& Nuske, E. (2016a). The public stigma of problem gambling: Its nature and relative intensity compared to other health conditions. Journal of Gambling Studies, 32(3), 847-864.

Hing, N., Russell, A., Tolchard, B., \& Nower, L. (2016b). Risk factors for gambling problems: An analysis by gender. Journal of Gambling Studies, 32(2), 511-534.

Hoorn, J., Crone, E. A., \& Leijenhorst, L. (2017). Hanging Out With the Right Crowd: Peer Influence on Risk- Taking Behavior in Adolescence. Journal of Research on Adolescence, 27(1), 189200.

Horch, J. D., \& Hodgins, D. C. (2008). Public stigma of disordered gambling: Social distance, dangerousness, and familiarity. Journal of Social and Clinical Psychology, 27(5), 505-528.

Huang, G. C., Unger, J. B., Soto, D., Fujimoto, K., Pentz, M. A., Jordan-Marsh, M., \& Valente, T. W. (2014). Peer influences: the impact of online and offline friendship networks on adolescent smoking and alcohol use. Journal of Adolescent Health, 54(5), 508-514.

Joinson, A. N. (2001). Self- disclosure in computer- mediated communication: The role of selfawareness and visual anonymity. European journal of social psychology, 31(2), 177-192.

King, D., Delfabbro, P., \& Griffiths, M. (2010). The convergence of gambling and digital media: Implications for gambling in young people. Journal of Gambling Studies, 26(2), 175-187. 
Kuss, D. J., Griffiths, M., Karila, L., \& Billieux, J. (2014). Internet addiction: a systematic review of epidemiological research for the last decade. Current Pharmaceutical Design, 20(25), 40264052 .

Lehdonvirta, V., \& Räsänen, P. (2011). How do young people identify with online and offline peer groups? A comparison between UK, Spain and Japan. Journal of Youth Studies, 14(1), 91108.

Lesieur, H. R., \& Blume, S. B. (1987). The South Oaks Gambling Screen (SOGS): A new instrument for the identification of pathological gamblers. American Journal of Psychiatry, 144(9).

Lind, K., Kääriäinen, J., \& Kuoppamäki, S. M. (2015). From problem gambling to crime? Findings from the Finnish national police information system. Journal of Gambling Issues, (30), 98123.

Livingstone, S., \& Helsper, E. J. (2007). Taking risks when communicating on the Internet: The role of offline social-psychological factors in young people's vulnerability to online risks. Information, Communication \& Society, 10(5), 619-644.

Lorains, F. K., Cowlishaw, S., \& Thomas, S. A. (2011). Prevalence of comorbid disorders in problem and pathological gambling: Systematic review and meta- analysis of population surveys. Addiction, 106(3), 490-498.

Martin, R. J., Usdan, S., Cremeens, J., \& Vail-Smith, K. (2014). Disordered gambling and comorbidity of psychiatric disorders among college students: An examination of problem drinking, anxiety and depression. Journal of Gambling Studies, 30(2), 321-333.

McNamara, N., \& Parsons, H. (2016). 'Everyone here wants everyone else to get better': The role of social identity in eating disorder recovery. British Journal of Social Psychology, 55(4), 662680.

Meerkerk, G. J., Van Den Eijnden, R. J., Vermulst, A. A., \& Garretsen, H. F. (2009). The compulsive internet use scale (CIUS): some psychometric properties. Cyberpsychology \& Behavior, 12(1), 1-6.

Mitchell, K. J., Finkelhor, D., Wolak, J., Ybarra, M. L., \& Turner, H. (2011). Youth internet victimization in a broader victimization context. Journal of Adolescent Health, 48(2), 128134.

Monaghan, S., \& Wood, R. T. (2010). Internet-based interventions for youth dealing with gambling problems. International journal of Adolescent Medicine and Health, 22(1), 113.

Mudry, T. E., \& Strong, T. (2013). Doing recovery online. Qualitative Health Research, 23(3), 313325. 
Noll, J. G., Shenk, C. E., Barnes, J. E., \& Haralson, K. J. (2013). Association of maltreatment with high-risk internet behaviors and offline encounters. Pediatrics, 131(2), e510-e517.

Oksanen, A., Aaltonen, M., \& Rantala, K. (2016). Debt problems and life transitions: a register-based panel study of Finnish young people. Journal of Youth Studies, 19(9), 1184-1203.

O’Leary, K., \& Carroll, C. (2013). The online poker sub-culture: Dialogues, interactions and networks. Journal of Gambling Studies, 29(4), 613-630.

Orford, J. (2001). Excessive Appetites: A Psychological View of Addictions. John Wiley \& Sons Ltd.

Parke, A., \& Griffiths, M. (2013). Poker gambling virtual communities: The use of ComputerMediated Communication to develop cognitive poker gambling skills. In Evolving Psychological and Educational Perspectives on Cyber Behavior (pp. 190-204). IGI Global.

Petry, N. M., Stinson, F. S., \& Grant, B. F. (2005). Comorbidity of DSM-IV pathological gambling and other psychiatric disorders: results from the National Epidemiologic Survey on Alcohol and Related Conditions. The Journal of Clinical Psychiatry, 66(5), 564-574.

Petry, N. M., \& Weiss, L. (2009). Social support is associated with gambling treatment outcomes in pathological gamblers. The American Journal on Addictions, 18(5), 402-408.

Petry, N. M., Blanco, C., Stinchfield, R., \& Volberg, R. (2013). An empirical evaluation of proposed changes for gambling diagnosis in the DSM- 5. Addiction, 108(3), 575-581.

Phillips, J. G., Ogeil, R. P., \& Blaszczynski, A. (2012). Electronic interests and behaviours associated with gambling problems. International Journal of Mental Health and Addiction, 10(4), 585596.

Raisamo, S., Halme, J., Murto, A., \& Lintonen, T. (2013). Gambling-related harms among adolescents: a population-based study. Journal of Gambling Studies, 29(1), 151-159.

Romanczuk-Seiferth, N., Van Den Brink, W., \& Goudriaan, A. E. (2014). From symptoms to neurobiology: pathological gambling in the light of the new classification in DSM-5. Neuropsychobiology, 70(2), 95-102.

Salonen, A., \& Raisamo, S. (2015). Suomalaisten rahapelaaminen 2015-Rahapelaaminen, rahapeliongelmat ja rahapelaamiseen liittyvät asenteet ja mielipiteet 15-74-vuotiailla. [Finnish gambling 2015. Gambling, gambling problems, and attitudes and opinions on gambling among Finns aged 15-74.] National Institute for Health and Welfare (THL). Report $16 / 2015$.

Shaffer, H. J., Hall, M. N., \& Vander Bilt, J. (1999). Estimating the prevalence of disordered gambling behavior in the United States and Canada: a research synthesis. American Journal of Public Health, 89(9), 1369-1376. 
Shead, N. W., Walsh, K., Taylor, A., Derevensky, J. L., \& Gupta, R. (2011). Youth gambling prevention: Can public service announcements featuring celebrity spokespersons be effective? International Journal of Mental Health and Addiction, 9(2), 165-179.

Sleczka, P., Braun, B., Piontek, D., Bühringer, G., \& Kraus, L. (2015). DSM-5 criteria for gambling disorder: Underlying structure and applicability to specific groups of gamblers. Journal of Behavioral Addictions, 4(4), 226-235.

Spada, M. M. (2014). An overview of problematic Internet use. Addictive Behaviors, 39(1), 3-6.

Splevins, K., Mireskandari, S., Clayton, K., \& Blaszczynski, A. (2010). Prevalence of adolescent problem gambling, related harms and help-seeking behaviours among an Australian population. Journal of Gambling Studies, 26(2), 189-204

Statistics Finland (2016) Population structure in Finland. Statistics Finland PX-Web Database. http://pxnet2.stat.fi/PXWeb/pxweb/fi/StatFin/. Accessed 15 August 2017.

Suler, J. (2004). The online disinhibition effect. Cyberpsychology \& Behavior, 7(3), 321-326.

Syed-Abdul, S., Fernandez-Luque, L., Jian, W. S., Li, Y. C., Crain, S., Hsu, M. H., ... \& Liou, D. M. (2013). Misleading health-related information promoted through video-based social media: anorexia on YouTube. Journal of Medical Internet Research, 15(2), e30.

Van Rooij, A., \& Prause, N. (2014). A critical review of "Internet addiction" criteria with suggestions for the future. Journal of Behavioral Addictions, 3(4), 203-213.

Volberg, R. A., Gupta, R., Griffiths, M. D., Ólason, D. T., \& Delfabbro, P. (2010). An international perspective on youth gambling prevalence studies. International Journal of Adolescent Medicine and Health, 22(1), 3-38.

WHO (2017) Gambling Disorder. In ICD-11 (beta draft). http://apps.who.int/classifications/icd11/browse/f/en\#/http\%3a\%2f\%2fid.who.int $\% 2$ ficd $\% 2 \mathrm{f}$ entity\%2f1041487064. Accessed 20 August 2017.

Worthy, S. L., Jonkman, J., \& Blinn-Pike, L. (2010). Sensation-seeking, risk-taking, and problematic financial behaviors of college students. Journal of Family and Economic Issues, 31(2), 161170. 
Tables

Table 1: Descriptive statistics of variables

\begin{tabular}{|c|c|c|c|c|c|c|}
\hline Discrete variables & $\mathbf{n}$ & $\%$ & & $\begin{array}{l}\%, \text { no at risk } \\
\text { gambling }\end{array}$ & $\begin{array}{l}\%, \text { at risk } \\
\text { gambling }\end{array}$ & $\begin{array}{l}\% \text {, probable } \\
\text { pathological } \\
\text { gambling }\end{array}$ \\
\hline All & 1200 & 100 & & 78.83 & 10.33 & 10.83 \\
\hline \multicolumn{7}{|l|}{ Online gambling communities } \\
\hline no & 1027 & 85.58 & & 84.42 & 9.15 & 6.43 \\
\hline yes & 173 & 14.42 & & 45.66 & 17.34 & 36.99 \\
\hline \multicolumn{7}{|l|}{ Gender } \\
\hline Female & 600 & 50.00 & & 88.00 & 7.33 & 4.67 \\
\hline Male & 600 & 50.00 & & 69.67 & 13.33 & 17.00 \\
\hline \multicolumn{7}{|l|}{ Age } \\
\hline $15-17$ & 215 & 17.92 & & 84.19 & 7.44 & 8.37 \\
\hline $18-21$ & 490 & 40.83 & & 73.67 & 11.02 & 15.31 \\
\hline $22-25$ & 495 & 41.25 & & 81.62 & 10.91 & 7.47 \\
\hline \multicolumn{7}{|l|}{ Instant loans } \\
\hline no & 1054 & 87.83 & & 81.88 & 9.49 & 8.63 \\
\hline yes & 146 & 12.17 & & 56.85 & 16.44 & 26.71 \\
\hline \multicolumn{7}{|l|}{ Online casino sites } \\
\hline no & 692 & 57.67 & & 91.18 & 5.2 & 3.61 \\
\hline yes & 508 & 42.33 & & 62.01 & 17.32 & 20.67 \\
\hline Continuous variables & Scale & Mean & SD & Mean & Mean & Mean \\
\hline Hazardous drinking (AUDIT C) & $0-13$ & 4.14 & 2.98 & 3.90 & 4.89 & 5.18 \\
\hline Compulsive internet use (CIUS) & $0-56$ & 18.79 & 11.13 & 17.74 & 22.75 & 22.65 \\
\hline Belonging to primary groups & $3-30$ & 20.19 & 6.14 & 20.53 & 19.67 & 18.21 \\
\hline
\end{tabular}


Table 2: At-risk gambling and pathological gambling by independent variables (relative-risk ratios, standard errors and p-values)

\begin{tabular}{|c|c|c|c|c|c|c|}
\hline & \multicolumn{3}{|c|}{$\begin{array}{l}\text { At-risk gambling } \\
\text { SOGS 3-4 }\end{array}$} & \multicolumn{3}{|c|}{$\begin{array}{c}\text { probable pathological } \\
\text { gambling } \\
\text { SOGS } \geq 5\end{array}$} \\
\hline & RRR & SE & $\mathbf{P}$ & RRR & SE & $\mathbf{P}$ \\
\hline Online gambling communities & 1.17 & 0.32 & .566 & 2.91 & 0.75 & $<.001$ \\
\hline Male & 2.14 & 0.47 & .001 & 3.70 & 0.95 & $<.001$ \\
\hline \multicolumn{7}{|l|}{ Age (ref. 22-25) } \\
\hline $15-17$ & 1.24 & 0.42 & .531 & 3.03 & 1.13 & .003 \\
\hline $18-21$ & 1.33 & 0.29 & .205 & 3.13 & 0.79 & $<.001$ \\
\hline Instant loans & 1.95 & 0.55 & .017 & 3.83 & 1.05 & $<.001$ \\
\hline Online casino sites & 4.04 & 0.96 & $<.001$ & 5.05 & 1.42 & $<.001$ \\
\hline Hazardous drinking (AUDIT C) & 1.07 & 0.04 & .059 & 1.07 & 0.04 & .078 \\
\hline Compulsive internet use (CIUS) & 1.05 & 0.01 & $<.001$ & 1.05 & 0.01 & $<.001$ \\
\hline Belonging to primary groups & 0.98 & 0.02 & .267 & 0.94 & 0.02 & $<.001$ \\
\hline
\end{tabular}

Note: no at-risk gambling is the reference category for the model. Model statistics: Nagelkerke pseudo- $\mathrm{R}^{2}=.33$; McFadden pseudo- $\mathrm{R}^{2}=.21$; Likelihood ratio $\chi^{2}=336.63, \mathrm{p}<.001$. 
Table 3: At-risk gambling and disordered gambling (DSM-5) by independent variables (relativerisk ratios, standard errors and p-values)

\begin{tabular}{|c|c|c|c|c|c|c|}
\hline & \multicolumn{3}{|c|}{$\begin{array}{l}\text { At-risk gambling } \\
\text { SOGS 3-7 }\end{array}$} & \multicolumn{3}{|c|}{$\begin{array}{c}\text { Disordered gambling } \\
\text { SOGS } \geq 8\end{array}$} \\
\hline & RRR & SE & $\mathbf{P}$ & RRR & SE & $\mathbf{P}$ \\
\hline Online gambling communities & 1.74 & 0.39 & .013 & 2.90 & 1.09 & .005 \\
\hline Male & 2.59 & 0.49 & $<.001$ & 3.60 & 1.48 & .002 \\
\hline \multicolumn{7}{|l|}{ Age (ref. 22-25) } \\
\hline $15-17$ & 1.67 & 0.48 & .071 & 3.58 & 2.79 & .102 \\
\hline $18-21$ & 1.79 & 0.34 & .002 & 3.72 & 1.78 & .006 \\
\hline Instant loans & 2.18 & 0.52 & .001 & 9.76 & 4.48 & $<.001$ \\
\hline Online casino sites & 4.10 & 0.83 & $<.001$ & 8.08 & 4.09 & $<.001$ \\
\hline Hazardous drinking (AUDIT C) & 1.07 & 0.03 & .023 & 1.06 & 0.06 & .304 \\
\hline Compulsive internet use (CIUS) & 1.05 & 0.01 & $<.001$ & 1.03 & 0.02 & .034 \\
\hline Belonging to primary groups & 0.97 & 0.01 & .023 & 0.91 & 0.03 & .001 \\
\hline
\end{tabular}

Note: no at-risk gambling is the reference category for the model. Model statistics: Nagelkerke pseudo- $\mathrm{R}^{2}=.34$; McFadden pseudo- $\mathrm{R}^{2}=.22$; Likelihood ratio $\chi^{2}=324.04, p<.001$. 